\title{
The systematic implications of leaf micromorphological characteristics in the tribe Neillieae (Spiraeoideae, Rosaceae)
}

\author{
Jun-Ho Song and Suk-Pyo Hong* \\ Laboratory of Plant Systematics, Department of Biology, Kyung Hee University, Seoul 02447, Korea \\ (Received 2 August 2017; Revised 24 August 2017; Accepted 18 September 2017)
}

\section{나도국수나무족(장미과) 잎 표피 미세형태학적 형질의 계통학적 유용성}

\author{
송준호 · 홍석표* \\ 경희대학교 이과대학 생물학과
}

\begin{abstract}
A comparative study of the leaf epidermal micromorphology in the tribe Neillieae (Neillia: 4 species, 4 varieties; Physocarpus: 5 species; Stephanandra: 2 species) was carried out using scanning electron microscopy in order to evaluate the taxonomic and systematic implications of these characteristics. The leaves of the genera Neillia and Stephanandra were hypostomatic, whereas those of P. monogynus, P. opulifolius were amphistomatic. The range of the size of the stomata is $12.02-34.39 \times 10.76-27.13 \mu \mathrm{m}$; the smallest was found in $N$. thyrsiflora (average $13.98 \times$ $12.43 \mu \mathrm{m} ; \mathrm{L} \times \mathrm{W}$ ), while the largest was measured in $N$. gracilis (average $26.82 \times 20.67 \mu \mathrm{m} ; \mathrm{L} \times \mathrm{W}$ ). Paracytic stomata complexes are only found in $N$. affinis, and the anomocytic type was most commonly found. The papillate epidermal cell type was only observed on the abaxial surfaces of $P$. insularis. Platelet epicuticular waxes were found on the adaxial surfaces of N. affinis and S. tanakae. Four types (unicellular non-glandular, two- to five-armed, stellate, and glandular) of trichomes were found on the leaves. Stellates were observed in all species of Physocarpus except for P. insularis. Consequently, leaf epidermal micromorphological characteristics (e.g., the presence of papillate epidermal cells and stellate, and stomata complexes) may have high taxonomic and systematic value in Neillieae. Our results strongly support previous molecular phylogenetic and palynological hypotheses that Stephanandra and Neillia are a single genus and that Physocarpus insularis should be considered as a member of Spiraea.
\end{abstract}

Keywords: Stomata complex, trichome, SEM, Physocarpus insularis, Neillieae, Rosaceae

적 요: 나도국수나무족에 속하는 Neillia속(나도국수나무속) 4종 4변종, Physocarpus속(산국수나무속) 5종, Stephanandra속(국수나무속) 2종을 포함, 총 3속 15분류군의 잎 표피 미세형태학적 형질을 주사전자현미경 (scanning electron microscope)을 이용하여 관찰 및 기재하였으며, 형질의 분류학적, 계통학적 유용성을 검토 하였다. Neillia속, Stephanandra속에서 기공복합체는 모두 배축면에만 존재하는 이면기공엽(hypostomatic type)이 나타났고, Physocarpus속에서는 P. monogynus, P. opulifolius에서만 양면기공엽(amphistomatic type)이 나타났다. 공변세포의 크기는 $12.02-34.39 \times 10.76-27.13 \mu \mathrm{m}$ 로 속과 종마다 다소 차이를 보이는데, $N$. thyrsiflora가 평균 $13.98 \times 12.43(\mathrm{~L} \times \mathrm{W}) \mu \mathrm{m}$ 로 가장 작은 공변세포를 갖는 것으로 나타났으며, N. gracilis가 평균 $26.82 \times 20.67(\mathrm{~L} \times \mathrm{W}) \mu \mathrm{m}$ 로 가장 크게 나타났다. 기공복합체의 형태는 N. affinis에서만 평행형 (paracytic)이 나타났고, 대부분 불규칙형(anomocytic)이 확인되었다. 표피세포는 섬국수나무(Physocarpus insularis)에서만 배축면에서 유두상(papillate)이 관찰되어 구별되었으며, N. affinis, S. tanakae의 향축면에서 판형(platelets)의 표피상납질(epicuticular wax)이 나타나 구별되었다. 한편, 연구된 분류군에서 모용은 크게

\footnotetext{
*Author for correspondence: sphong@khu.ac.kr
} 
단세포단모(unicellular non-glandular trichome), 2-5개 가지상 모용(two- to five-armed trichome), 성상모 (stellate), 선모(glandular trichome), 총 4종류로 확인되었다. 특히, 섬국수나무를 제외한 Physocarpus속 모든 분류군에서 성상모가 나타나 구별되었다. 끝으로, 잎 표피 미세형태학적 형질 중 기공복합체의 형태, 유두상 표피세포의 유무, 성상모의 유무 형질이 분류학적 및 계통학적으로 유용성이 있음을 밝혔고, 본 연구 결과, Stephanandra속의 Neillia속으로의 통합, 섬국수나무(Physocarpus insularis)의 Spiraea속(조팝나무속)으로의 전 속을 주장한 이전의 분자계통학적 및 화분학적 연구 결과를 강력하게 지지하였다.

주요어: 기공복합체, 모용, $\mathrm{SEM}$, 섬국수나무, 나도국수나무족, 장미과

나도국수나무족(tribe Neillieae Maxim.)은 장미과(family Rosaceae Juss.) 내의 조팝나무아과(subfamily Spiraeoideae Agardh)에 속하는 분류군으로 Neillia D. Don (나도국수나 무속), Physocarpus (Cambess.) Raf. (산국수나무속), Stephanandra Siebold \& Zucc. (국수나무속)를 포함한 약 18 분류군으로 구성된다(Maximowicz, 1879; Schulze-Menz, 1964). 본 족은 주로 동아시아와 북미 등 북반구 온대지역 에 분포하는데, 특히 Neillia속, Stephanandra속, Physocarpus amurensis는 동아시아에 제한적으로 분포하고, P. alternans, P. capitatus, P. malvaceus, P. monogynus는 북미 서부에 자생 하며, P. opulifolius는 북미 동부에 분포한다(Oh and Potter, 2005). 본 족에 속하는 분류군은 관목, 결각상의 호생하는 단엽, 숙존성 또는 낙엽성 탁엽의 존재, 골돌과 내 많은 양 의 배유를 갖는 종자 등, 조팝나무족, 쉬땅나무족 등의 과 내 다른 분류군과 구별되는 형질을 지닌다(Vidal, 1963; Kalkman, 2004).

최근 수행된 분자계통학적 연구 결과에서는 장미과 내 나도국수나무족의 단계통을 강력히 지지하고 있으나 (Morgan et al., 1994; Potter et al., 2002; Oh and Potter, 2005), 족 내 속간 한계 설정에 대해서는 학자 간의 의견이 다양하 다. Bentham and Hooker (1865), Greene (1889), Jones (1893) 는 나도국수나무족이 2개의 속(Neillia속[Physocarpus속 포 함], Stephanandra속)으로 이루어진 것으로 규정한 반면, Kuntze (1891)는 족에 포함되는 세 속을 Physocarpus 하나 의 속으로 인식하였다. 대부분의 학자들은 전통적으로 본 족을 Neillia속, Physocarpus속, Stephanandra속, 3개의 속으 로 인식하였고, 최근까지도 나도국수나무족은 3 개의 속 으로 인식되어 왔다(Rehder, 1940; Schulze-Menz, 1964; Robertson, 1974; Takhtajan, 1997; Kalkman, 2004).

하지만, 가장 최근에 수행된 엽록체 DNA, 핵 DNA, $L E A F Y$ 를 이용한 분자계통학적 연구에서는 Stephanandra 속이 Neillia속으로 유합되는 결과를 통해 두 속의 통합을 제안하였고(Oh and Potter, 2003, 2005), Stephanandra속이 Neillia속으로 통합되며 Stephanandra속 내 분류군들이 명 명법적 규약에 의거하여 재조합되었다(Oh, 2006). 이처럼, 가장 최근의 장미과 분류체계에서는 본 족을 Neillia속과 Physocarpus속 두 속으로 인식하고 있다(Potter et al., 2007). 한편, 나도국수나무족 산국수나무속 내에 포함되는 분류 군인 섬국수나무[Physocarpus insularis (Nakai) Nakai]는 최
근까지도 분류학적 위치에 대한 다양한 의견이 있어 왔다. Kim et al. (2000)은 형태학적 형질을 통해 섬국수나무를 Spiraea chamaedryfolia L. var. ulmifolia (Scop.) Maxim. (인 가목조팝나무)의 이명으로 처리하였고, Oh et al. (2010)은 형태학적, 분자계통학적 결과의 종합적 고찰을 통해 섬국 수나무를 Spiraea L. (조팝나무속) 내에 포함되나, 인가목 조팝나무와는 다른 종으로 구별하여 인식하였다. 그 결과, 섬국수나무는 Physocarpus속에서 Spiraea속으로 전속되어, S. insularis (Nakai) H. Shin, Y. D. Kim \& S. H. Oh로 재조합 되었다(Shin et al., 2011).

하지만, 섬국수나무를 포함한 본 족에 대한 연구는 일부 외부형태와 분자계통학적 형질에만 국한되어있고, 미세 형태학적 형질에 대한 연구는 미비한 실정이다. 잎 표피, 꽃잎 표피, 종자 표면 등의 미세형태학적 형질은 해당 식 물군의 진화와 분류, 계통학적 해석에 있어 유용한 정보 를 제공해주며, 나아가 피자식물군 전체의 종합적인 이해 를 돕는다(Dahlgren, 1980; Moïse et al., 2005). 특히, 잎 표피 미세형태학적 형질은 형질의 기재 및 분류학적 유용성이 이미 검증된 바 있으며(Wilkinson, 1979; Stace, 1984), 최근 까지도 이와 같은 분류학적 유용성을 근거로 오미자과 (Yang and Lin, 2005), 가지속(Anil Kumar and Murugan, 2013), 토끼풀속(Zoric et al., 2009), Cyclobalanopsis아속 (Deng et al., 2014), Glyptostrobus pensilis (Ma et al., 2004) 등 다양한 분류군의 다양한 분류학적 계급 내에서 분류학 적 및 계통학적으로 적용되어 왔다. 한편, 잎 표피에서 관 찰할 수 있는 형질들 가운데 기공의 형태와 밀도, 모용의 종류와 분포 및 표피상납질의 유무 등은 박하족(Moon et al., 2009), 쉬땅나무족(Song and Hong, 2016), 양지꽃족(Heo et al., 2013), 토끼풀족(Taia, 2004), Crotoneae족(De Sá-Haiad et al., 2009), Saturejeae족(Husain et al., 1990) 등 족 수준에서 속간 또는 종간 분류학적 유용성이 검증되었다.

이에, 본 연구에서는 나도국수나무족 3속 15 분류군을 대상으로 주사전자현미경(scanning electron microscope, $\mathrm{SEM})$ 을 이용하여, 잎 표피에서 확인할 수 있는 기공, 표피 세포, 표피상납질, 모용 등의 미세형태학적 형질을 살펴 보고자 하였다. 따라서, 본 연구는 나도국수나무족에 포 함되는 분류군의 잎 표피 미세형태를 상세히 관찰하고, 기재하며, 확인된 잎 표피 미세형태학적 형질과 최근 분 자계통학적 연구와의 비교 고찰을 통해 형질의 계통학적 
유용성 및 족 내 속간 진단형질로서의 가치를 파악하고자 처음으로 시도되었다. 또한, 최근 Spiraea속으로 전속된 섬국수나무와 Spiraea속 분류군 잎 표피 연구와의 비교를 통해 섬국수나무의 분류학적 위치에 대한 타당성을 확인 하는 데 그 의의가 있다.

\section{재료 및 방법}

본 연구에서는 Neillia속(나도국수나무속) 4종 4변종, Physocarpus 속(산국수나무속) 5종, Stephanandra속(국수나 무속) 2 종, 총 3 속 15 분류군의 석엽 표본 또는 생체 표본을 국내·외 표본관(KB, KHUS, WU, abbreviations according to Thiers, 2017)으로부터 대여하거나 직접 채집하여 사용하였 으며, 실험에 사용된 확증표본은 Appendix 1에 제시하였다.

성숙한 잎을 선별하고, 모용과 선점을 관찰하기 위해 해 부현미경(streomicroscope, SteREO Discovery. V8, Carl Zeiss Microscopy $\mathrm{GmbH}$, Jena, Germany)을 사용하였으며, 주사 전자현미경(SEM)을 이용하여 잎 표피 미세형질들을 관 찰하였다. 야외에서 직접 채집된 생체표본은 $\mathrm{FAA}(40 \%$ formalin: $40 \%$ glacial acetic acid: $70 \%$ ethyl alcohol) mixture 에 고정 후 장기 보관하여 사용하였고, 이미 건조된 표본이 나, 대출표본으로부터의 재료는 약 $90^{\circ} \mathrm{C}$ 에서 3 분간 끓이거 나 연화제(Agepon, Agfa Gevaert, Leverkusen, Germany; Agepon wetting agent : distilled water, $1: 200$ )에 넣어, 24시 간 이상 담가 조직을 부드럽게 한 후, $70 \%$ alcohol에 보관 하여 실험에 사용하였다. 잎의 미세형태학적 형질을 관찰 하기 위해서 $70 \%$ alcohol에 보관된 시료는 아세톤시리즈 (acetone series: $50 \%, 70 \%, 90 \%, 100 \%$ 에서 각각 약 1 시간 정 도 보관)를 거쳐 탈수한 후, 이산화탄소 $\left(\mathrm{CO}_{2}\right)$ 가스를 이용 한 임계점 건조 처리(critical point drying; SPI-13200J-AB, SPI Supplies, West Chester, PA, USA)를 하여 완전 건조시켰 다. 건조된 시료는 알루미늄 스터브(aluminum stub) 위에 올린 다음 이온 증착기(Ion-Sputter, JFC-1100, JEOL, Tokyo, Japan)를 이용하여 백금(Pt)으로 2분간 이온증착(ion-coating) 하였으며, 전계방출형 주사전자현미경(field emission scanning electron microscope; FE-SEM, S-4700, Hitachi, Tokyo, Japan)으로 WD (working distance) 10-12 mm와, 가속전력 $10 \mathrm{kv}$ 에서 관찰하였다. 기공의 크기와 모용의 길이는 Macnification program (2.0 version, Orbicule, Leuven, Belgium)으로 측정하였고, 기공의 크기는 25 개를 최소단 위로 측정하여, 최소-(평균)-최대값으로 나타냈으며, 기 공의 밀도는 일정 면적 $\left(0.05 \mathrm{~mm}^{2}\right)$ 에 분포하는 수를 세었 다. 또한, 기공의 길이 $(\mathrm{L})$, 너비 $(\mathrm{W})$, 밀도(D) 간의 관계를 파악하기 위해 피어슨 상관관계(Pearson correlation)를 이 용하여 분석하였다(IBM SPSS Statistics for Windows, version 19.0, Released 2010, IBM Corp., Armonk, NY, USA).

잎 표피 미세형질에 관한 용어는 Wilkinson (1979), Barthlott (1981), Stace (1984)를 주로 따랐고, 모용의 형태
는 Theobald et al. (1979)을 참고하였다.

\section{결 과}

본 연구결과 확인된 나도국수나무족 15 분류군의 잎 표 피 미세형태학적 형질은 Tables 1과 2에 정리하였으며, Figs. 1-4에 제시하였다.

\section{기공복합체(stomatal complex)의 유형}

나도국수나무족 분류군의 기공복합체는 Neillia속, Stephanandra속에서 배축면(abaxial surface)에만 기공이 존 재하는 이면기공엽(hypostomatic type)이었고, Physocarpus 속에서는 P. monogynus, P. opulifolius에서만 배축면과 향축 면(adaxial surface) 모두에 기공이 존재하는 양면기공엽 (amphistomatic type)으로 나타났다(Fig. 2A, B, Table 1). 공

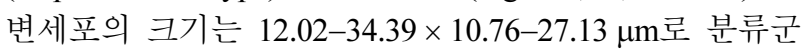
에 따라 다소 차이를 보이는데, N. thyrsiflora가 평균 $13.98 \times 12.43(\mathrm{~L} \times \mathrm{W}) \mu \mathrm{m}$ 로 가장 작은 공변세포를 갖는 것 으로 나타났으며, N. gracilis가 평균 $26.82 \times 20.67(\mathrm{~L} \times \mathrm{W})$ $\mu \mathrm{m}$ 로 가장 크게 나타났다(Table 1). 기공의 길이 $(\mathrm{L})$ 와 너비 (W) 간에는 유의한 수준으로 양의 상관관계를 나타냈고 $(\mathrm{L}$ 과 $\mathrm{W}: \mathrm{r}=0.72, p<0.001)$, 기공의 길이와 너비는 밀도 (D)와 유의한 수준으로 음의 상관관계를 나타냈다 $(\mathrm{L}$ 과 $\mathrm{D}: \mathrm{r}=-0.50, p<0.001 ; \mathrm{W}$ 와 $\mathrm{D}: \mathrm{r}=-0.28, p<0.05)$. 기공복합체 의 형태는 대부분의 분류군에서 불규칙형(anomocytic)이 관 찰되었으며(Table 1), N. affinis에서만 평행형(paracytic)이 나타났다(Fig. 1A).

\section{표피세포(epidermal cell)의 미세형태 및 표피상납 질의 유무}

표피세포의 형태는 연구된 모든 분류군에서 등방형 (isodiametric)으로 나타났고, 부세포의 수층벽(anticlinal wall)은 Neillia속의 향축면에서 모두 직선형과 곡선형이 동시에 관찰(straight/curved)되었으며, 배축면에서 파상형 (undulate)이 나타났고(Fig. 1A, G), Physocarpus속에서는 직 선형(straight), 곡선형(curved), 파상형이 동시에 나타났다. 반면, Stephanandra속에서는 향축면, 배축면 모두에서 파 상형이 관찰되었다(Table 2). 병층벽(periclinal wall)의 형태 는 대부분의 분류군에서 향축면, 배축면에서 편평(flat)하 게 나타났지만, 섬국수나무(P. insularis)의 배축면에서만 유두상(papillate)이 나타났으며(Fig. 1I-J), Stephanandra속 내 분류군의 배축면에서는 볼록(convex)하게 나타났다. 표 피세포의 표면(fine relief)은 매끈하거나(Fig. 1K), 유선상 의 표면을 지닌다(Fig. 1B, E, Table 2).

연구된 분류군 중 판형(platelets)의 표피상납질은 일부 분류군에서만 관찰되었는데, Neillia affinis (Fig. 1C), Stephanandra tanakae (Fig. 2E)의 향축면에서만 확인되었 다(Table 2). 
Table 1. Overview of representative stomatal characters on leaves of all taxa studied in the tribe Neillieae.

\begin{tabular}{|c|c|c|c|c|c|c|}
\hline \multirow{2}{*}{ Taxa } & \multicolumn{4}{|c|}{ Stomata complex } & \multicolumn{2}{|c|}{ Size of stomata $(\mu \mathrm{m})$} \\
\hline & Position & & Type & $\mathrm{SP}^{\mathrm{a}}$ & Length & Width \\
\hline \multicolumn{7}{|l|}{ Genus Neillia } \\
\hline Neillia affinis & HP & $\mathrm{AB}$ & Para & $20-31$ & $19.65-(21.71)-23.32$ & $18.63-(20.74)-22.13$ \\
\hline Neillia gracilis & HP & $\mathrm{AB}$ & Ano & $9-12$ & $22.50-(26.82)-34.39$ & $10.76-(20.67)-24.74$ \\
\hline Neillia sinensis var. sinensis & HP & $\mathrm{AB}$ & Ano & $7-15$ & $18.85-(22.73)-25.87$ & $15.72-(17.87)-20.52$ \\
\hline Neillia sinensis var. hypomalaca & HP & $\mathrm{AB}$ & Ano & $18-23$ & $13.04-(17.32)-20.71$ & $13.00-(16.61)-19.42$ \\
\hline Neillia thibetica var. thibetica & HP & $\mathrm{AB}$ & Ano & $7-10$ & $15.83-(20.21)-24.78$ & $12.83-(17.13)-20.26$ \\
\hline Neillia thibetica var. lobata & HP & $\mathrm{AB}$ & Ano & $15-18$ & $16.46-(19.86)-23.15$ & $12.15-(17.05)-20.77$ \\
\hline Neillia thyrsiflora & HP & $\mathrm{AB}$ & Ano & $32-46$ & $12.02-(13.98)-16.90$ & $11.10-(12.43)-14.60$ \\
\hline Neillia uekii & HP & $\mathrm{AB}$ & Ano & $8-11$ & $17.76-(21.90)-24.25$ & $14.42-(16.01)-18.56$ \\
\hline \multicolumn{7}{|l|}{ Genus Physocarpus } \\
\hline Physocarpus amurensis & HP & $\mathrm{AB}$ & Ano & $9-13$ & $13.61-(15.79)-18.52$ & $13.24-(14.58)-16.54$ \\
\hline Physocarpus insularis & HP & $\mathrm{AB}$ & Ano & $14-22$ & $15.62-(18.23)-20.53$ & $14.66-(17.13)-19.87$ \\
\hline Physocarpus malvaceus & HP & $\mathrm{AB}$ & Ano & $24-32$ & $13.85-(15.43)-19.09$ & $11.76-(14.10)-17.63$ \\
\hline \multirow[t]{2}{*}{ Physocarpus monogynus } & $\mathrm{AM}$ & $\mathrm{AD}$ & Ano & $1-4$ & $17.63-(22.27)-26.63$ & $14.83-(17.54)-22.28$ \\
\hline & & $\mathrm{AB}$ & Ano & $12-13$ & $15.38-(20.02)-24.63$ & $13.77-(16.78)-27.13$ \\
\hline \multirow[t]{2}{*}{ Physocarpus opulifolius } & $\mathrm{AM}$ & $\mathrm{AD}$ & Ano & $1-2$ & $24.24-(26.09)-29.94$ & $16.86-(19.05)-21.52$ \\
\hline & & $\mathrm{AB}$ & Ano & $10-13$ & $19.56-(23.29)-28.87$ & $12.99-(16.82)-21.27$ \\
\hline \multicolumn{7}{|l|}{ Genus Stephanandra } \\
\hline Stephanandra incisa & HP & $\mathrm{AB}$ & Ano & $7-11$ & $15.82-(20.53)-24.89$ & $16.84-(18.71)-21.70$ \\
\hline Stephanandra tanakae & HP & $\mathrm{AB}$ & Ano & $10-18$ & $14.13-(18.11)-22.57$ & $14.02-(16.74)-20.99$ \\
\hline
\end{tabular}


Table 2. Overview of representative leaf epidermal surface micromorphological characters, kinds of trichomes and epicuticular waxes on leaves of all taxa studied in the tribe Neillieae.
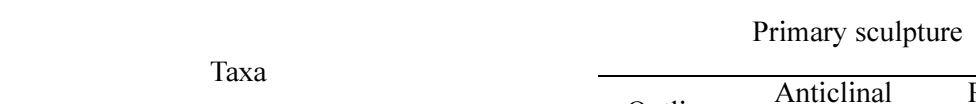

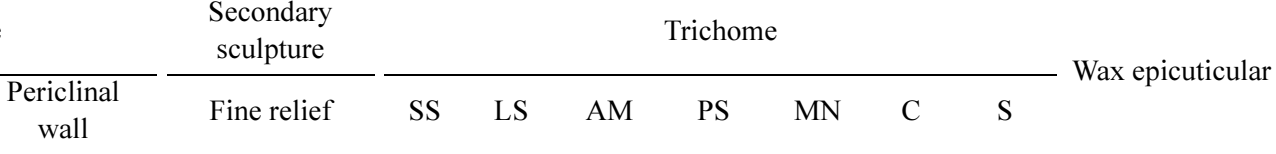

\section{Genus Neillia}

Neillia affinis

Outline wall wal

$\begin{array}{lll} & \\ - & + \\ + & + \\ - & + \\ + & + \\ - & + \\ - & + \\ + & + \\ ++ & + \\ ++ & + \\ ++ & + & \\ ++ & + \\ + & + \\ ++ & + \\ + & + \\ - & + \\ + & +\end{array}$

\section{Genus Physocarpus}

Physocarpus amurensis

Physocarpus insularis

Physocarpus malvaceus

Physocarpus monogynus

$\begin{array}{ccc}\mathrm{AD} & \text { iso } & \text { cur/st } \\ \mathrm{AB} & \text { iso } & \text { und } \\ \mathrm{AD} & \text { iso } & \text { cur/st } \\ \mathrm{AB} & \text { iso } & \text { und } \\ \mathrm{AD} & \text { iso } & \text { und } \\ \mathrm{AB} & \text { iso } & \text { und } \\ \mathrm{AD} & \text { iso } & \text { cur/st } \\ \mathrm{AB} & \text { iso } & \text { und } \\ \mathrm{AD} & \text { iso } & \text { cur/st } \\ \mathrm{AB} & \text { iso } & \text { und } \\ \mathrm{AD} & \text { iso } & \text { cur/st } \\ \mathrm{AB} & \text { iso } & \text { und } \\ \mathrm{AD} & \text { iso } & \text { cur/st } \\ \mathrm{AB} & \text { iso } & \text { und } \\ \mathrm{AD} & \text { iso } & \text { cur/st } \\ \mathrm{AB} & \text { iso } & \text { und }\end{array}$

$\mathrm{ft}$
$\mathrm{ft}$
$\mathrm{ft}$
$\mathrm{ft}$
$\mathrm{ft}$
$\mathrm{ft}$
$\mathrm{ft}$
$\mathrm{ft}$
$\mathrm{ft}$
$\mathrm{ft}$
$\mathrm{ft}$
$\mathrm{ft}$
$\mathrm{ft}$
$\mathrm{ft}$
$\mathrm{ft}$
$\mathrm{ft}$

$\begin{array}{llc}\mathrm{AD} & \text { iso } & \text { cur/st } \\ \mathrm{AB} & \text { iso } & \text { und }\end{array}$

$\mathrm{AD}$ iso und

$\begin{array}{llc}\mathrm{AD} & \text { iso } & \mathrm{cur} / \mathrm{st} \\ \mathrm{AB} & \text { iso } & \mathrm{cur}\end{array}$

$\mathrm{AD}$ iso cur

$\mathrm{AD}$ iso

$\mathrm{AB}$ iso cur/st

Physocarpus opulifolius

Genus Stephanandra

Stephanandra incisa

$\begin{array}{lllll}\mathrm{AD} & \text { iso } & \text { und } & \mathrm{ft} & \mathrm{st} \\ \mathrm{AB} & \text { iso } & \text { und } & \mathrm{cv} & \mathrm{sm} \\ \mathrm{AD} & \text { iso } & \text { und } & \mathrm{ft} & \mathrm{st} \\ \mathrm{AB} & \text { iso } & \text { und } & \mathrm{cv} & \mathrm{sm}\end{array}$

st
sm
st
st
st
st
st
st
st
st
st
st
st
sm
st
sm

Stephanandra tanakae

$\mathrm{AB}$ iso und

$$
\begin{gathered}
\text { st } \\
\text { st } \\
\text { sm } \\
\text { sm } \\
\text { st } \\
\text { st } \\
\text { st } \\
\text { st } \\
\text { st } \\
\text { st }
\end{gathered}
$$$$
\text { st }
$$

Outline: iso, isodiametric. Anticlinal wall: st, straight; cur, curved; und, undulate. Periclinal wall: cv, convex; ft, flat; pa, papillate. Fine relief: sm, smooth; st, striation. Trichome: SS, short unicellular non-glandular trichome; LS, long unicellular non-glandular trichome; AM, two- to five-armed trichome; PS, sessile porrect-stellate trichome; MN, sessile multi-angular stellate trichome; $\mathrm{C}$, capitate gland; $\mathrm{S}$, subsessile gland. Epicuticular wax: pt, platelets. $\mathrm{AB}$, abaxial side; $\mathrm{AD}$, adaxial side; -, absent; +, present; ++, dominance; +++, more dominance. 

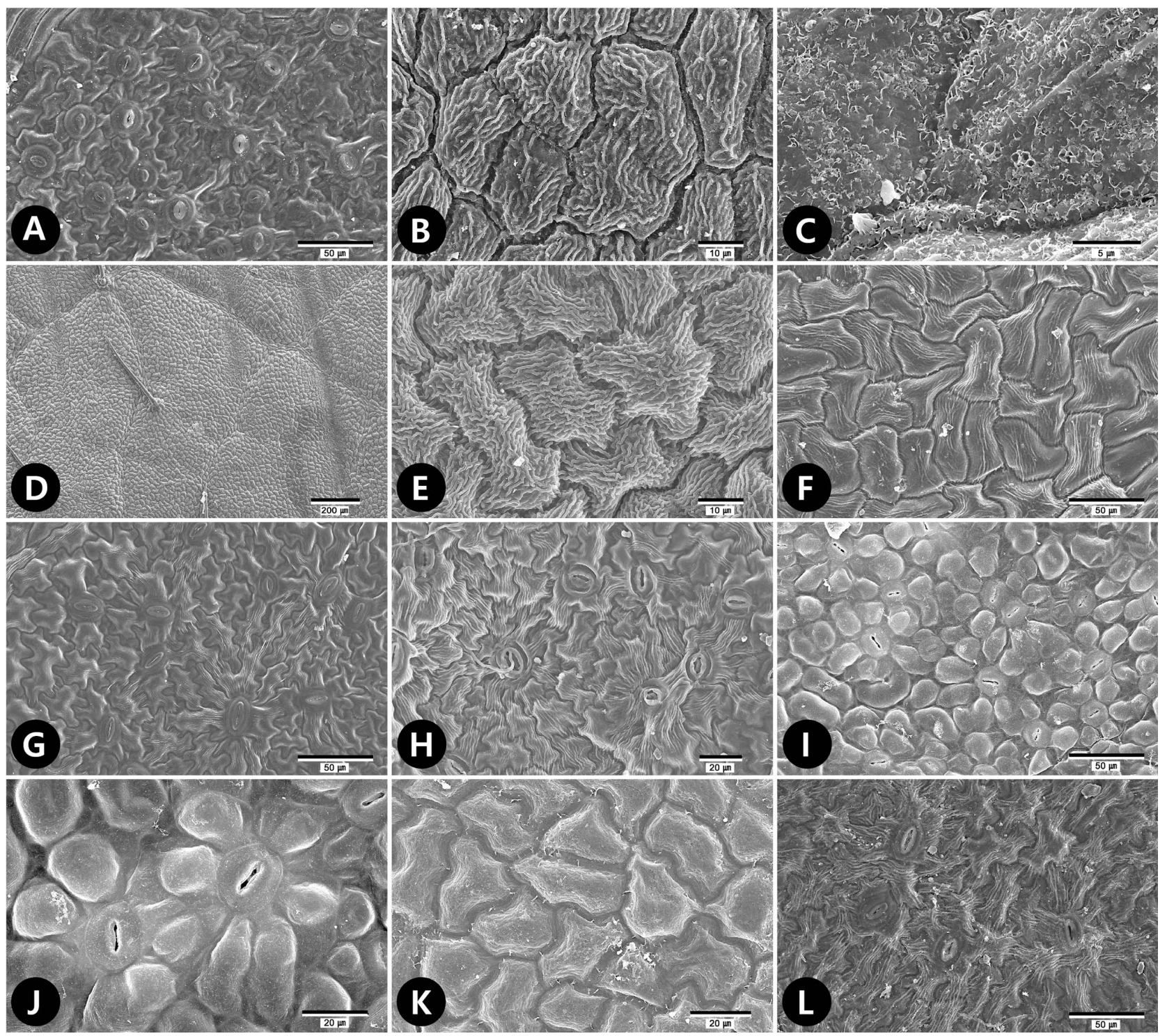

Fig. 1. Scanning electron microscope micrographs of leaf surfaces of tribe Neillieae. A-C. Neillia affinis. A. Abaxial surface showing undulate anticlinal walls with paracytic stomata. B. Adaxial surface showing straight and curved epidermal cells with striation fine relief. C. Platelets epicuticular waxes deposit at the adaxial surface. D, E. Neillia sinensis var. sinensis. D. Adaxial surface showing isodiametric epidermal cells. E. Adaxial surface showing undulate anticlinal walls with striation fine relief. F. Neillia thibetica var. thibetica. Adaxial surface showing straight and curved epidermal cells. G. Neillia uekii. Abaxial surface showing undulate anticlinal walls with anomocytic stomata. H. Physocarpus amurensis. Abaxial surface showing undulate anticlinal walls with anomocytic stomata. I-K. Physocarpus insularis. I, J. Abaxial surface showing curved anticlinal walls and papillate periclinal walls with anomocytic stomata. K. Adaxial surface showing straight and curved epidermal cells with smooth fine relief. L. Physocarpus monogynus. Adaxial surface showing undulate anticlinal walls with anomocytic stomata.

\section{모용(trichome)의 유형}

연구된 15 분류군의 잎 표피에는 향축면과 배축면에 다 양한 종류의 모용이 분포하는 것으로 밝혀졌다. 비선모 모 용은 단세포 단모(simple unbranched unicellular non-glandular trichome)와 2-5개 가지상 모용(two- to five-armed trichome), 성상모(stellate)가 나타났고, 선모(glandular trichome)는 짧
은 자루의 두상선모(capitate glandular trichome)와 자루가 없는 두상선모(subsessile glandular trichome)가 나타났다. 모용의 종류에 따라 다음의 type과 subtype으로 구별하였 다(Table 2).

1. Type 1 . 단세포 단모 

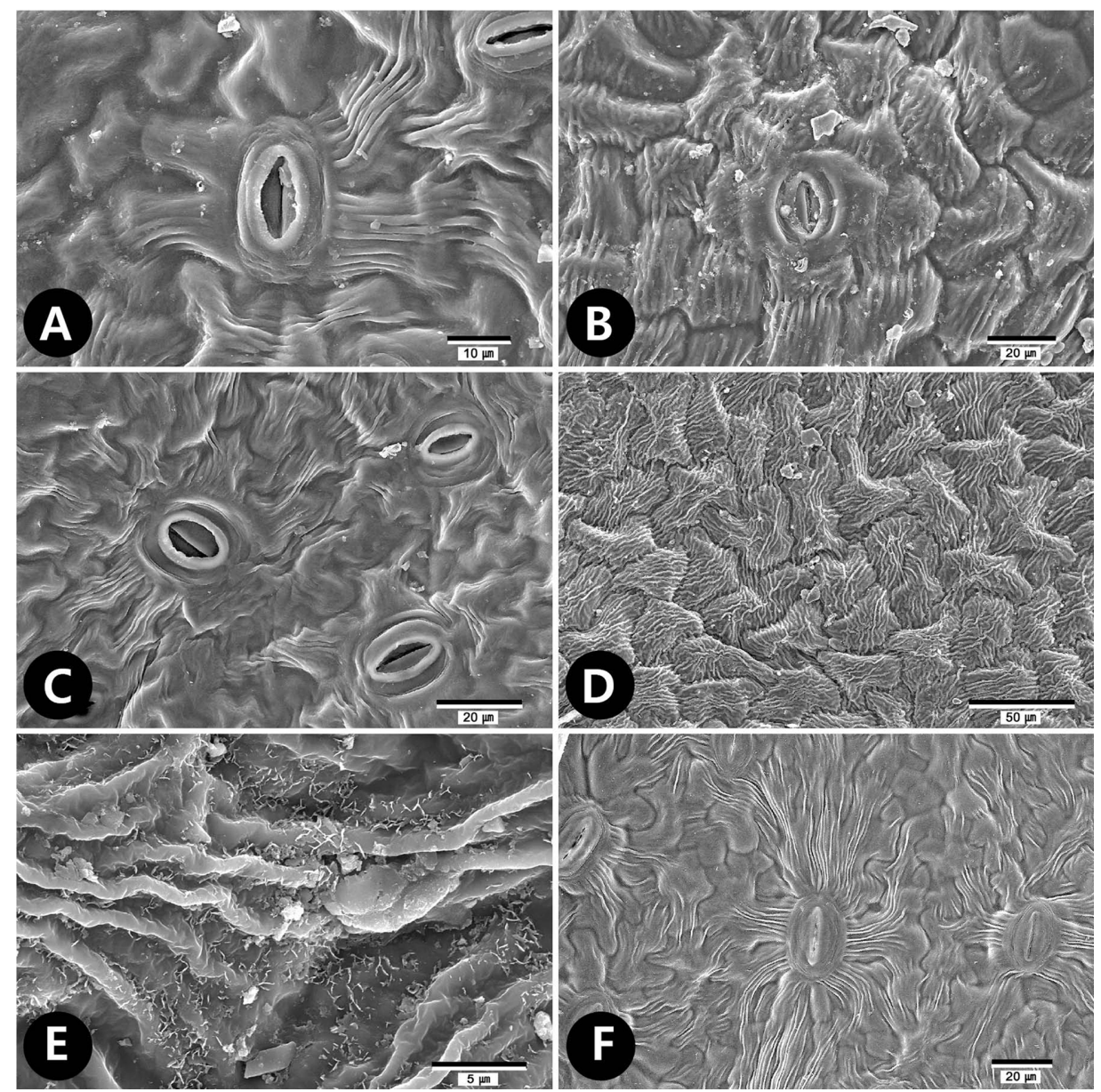

Fig. 2. Scanning electron microscope micrographs of leaf surfaces of tribe Neillieae. A, B. Physocarpus opulifolius. A. Abaxial surface showing anomocytic stomata. B. Adaxial surface showing anomocytic stomata. C-E. Stephanandra tanakae. C. Abaxial surface showing anomocytic stomata. D. Abaxial surface showing undulate anticlinal walls with striation fine relief. E. Adaxial surface showing platelets epicuticular waxes. F. Stephanandra incisa. Abaxial surface showing anomocytic stomata.

단세포성 단모로, 표면이 매끈하며, 모용의 길이에 따라 2가지 subtype으로 구별된다.

1) subtype 1-1. 짧은 단모(short trichome, SS)

길이 $100 \mu \mathrm{m}$ 이하의 짧은 단모로 Neillia속 대부분의 분 류군과 Stephanandra속에서 나타났다(Figs. 3G, 4K).

2) subtype 1-2. 긴 단모(long trichome, LS)

$100 \mu \mathrm{m}$ 이상의 길이를 지닌 단모로 연구된 대부분의 분 류군에서 나타났고, 특히 Neillia속 대부분에서 높은 빈도 로 확인되었다(Figs. 3B-J, L, 4L).

\section{Type 2. $2-5$ 개 가지상 모용}

2 개에서 5 개의 가지로 구성된 모용으로, 각 가지는 단세 포이다. 특히 2개, 4 개 가지상 모용이 주로 나타난다. 연구 된 분류군 가운데, P. malvaceus, P. monogynus 분류군에서
만 향축면, 배축면에서 관찰되었다(Fig. $4 \mathrm{~B}, \mathrm{G}, \mathrm{H})$.

\section{Type 3. 성상모}

6개 이상의 가지로 구성된 별 모양(star-shaped)의 비선 모로 성상모를 이루는 ray (가지상 단모)의 빈도와 모양에 따라 2가지 subtype으로 구별된다.

1) subtype 3-1. 수평으로 납작한 형태의 성상모(porrectstellate trichome, PS)

Horizontal rays (수평으로 위치한 6-8개의 가지상 단모) 로 이루어진 성상모로, 각 ray는 수평으로 돌려나며(rotate) 하나의 평면에 배열한다(Fig. $4 \mathrm{C}, \mathrm{I}, \mathrm{J})$. 연구된 분류군 가운 데 섬국수나무(P. insularis)를 제외한 Physocarpus 속 모든 분류군의 양면에서 관찰되었다.

2) subtype 3-2. 다각상 성상모(multi-angulate trichome, $\mathrm{MN}$ ) 

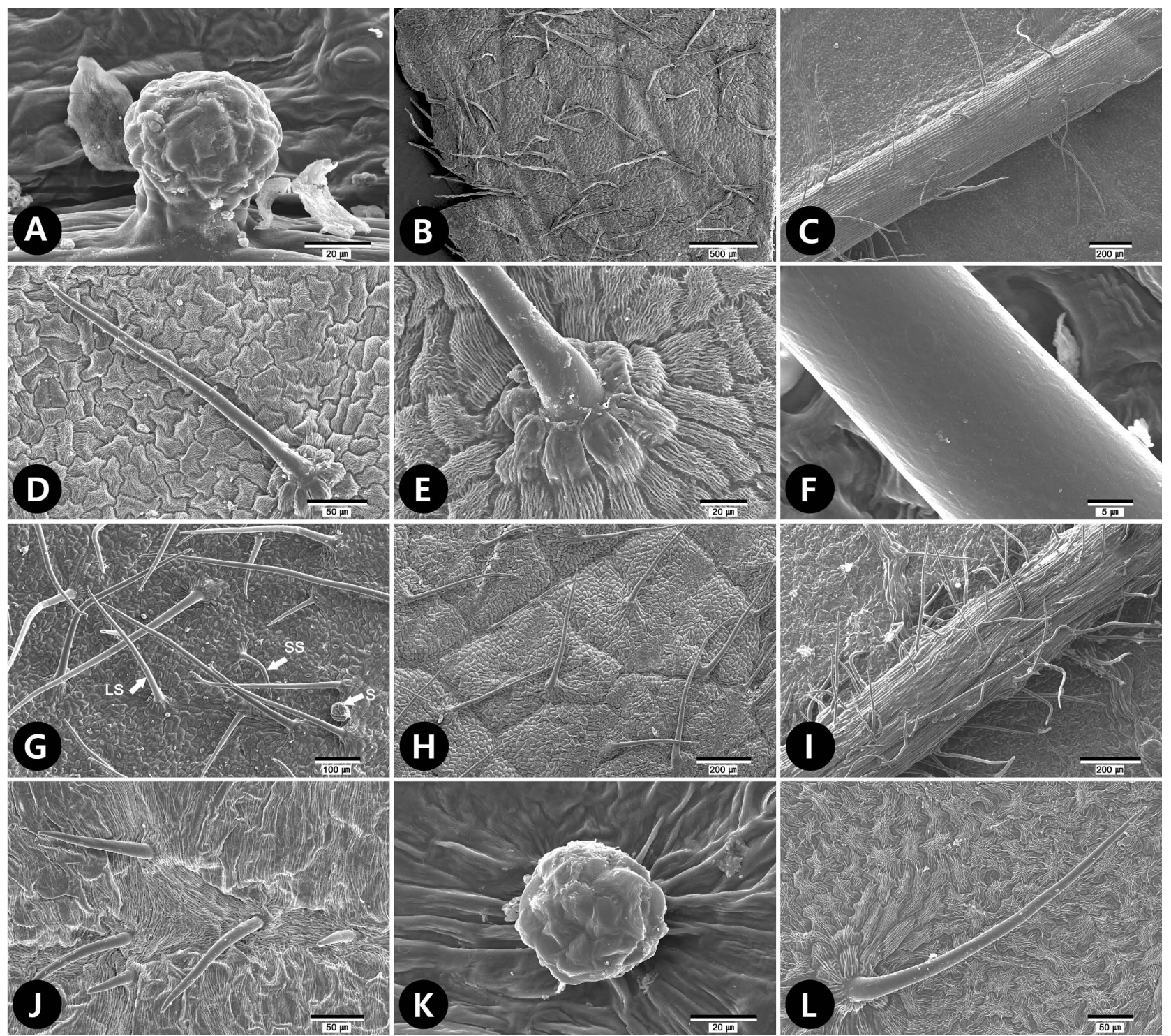

Fig. 3. Scanning electron microscope micrographs of trichomes of tribe Neillieae. A. Neillia affinis. Capitate glandular trichome (type 4-1). B. Neillia gracilis. Distribution of long trichome (>100 $\mathrm{m}$, LS, type 1-2) at adaxial surface. C-E. Neillia sinensis var. sinensis. C. Distribution of LS (type 1-2) at abaxial surface mid vein. D, E. Unicellular LS (type 1-2) of adaxial surface. F-H. Neillia sinensis var. hypomalaca. F. Trichome surface showing smooth wall. G. Each arrows indicate short trichome (SS, type 1-1), LS (type 1-2), and subsessile glandular trichome (S, type 4-2) at abaxial surface, respectively. H. Distribution of LSs (type 1-2) at adaxial surface. I. Neillia thibetica var. thibetica. Distribution of LS (type 1-2) at abaxial surface mid vein. J. Neillia thibetica var. lobata. SS (type 1-1) and LS (type 1-2) at adaxial surface. K. Neillia thyrsiflora. S (type 4-2) at abaxial surface. L. Neillia uekii. LS (type 1-2) at adaxial surface.

10 개 이상의 ray가 다각상으로 위치한 성상모로, 각 ray 가 자루(stalk)을 중심으로 다각상으로 배열하거나, 자루 가 없이 central ray (중앙단모)를 중심으로 다각상으로 배열 한다(Fig. 4C-E). 연구된 분류군 내에서 섬국수나무를 제외 한 Physocarpus속 모든 분류군의 양면에서 관찰되었다.

\section{Type 4. 선모}

다세포성 선모로, 자루의 유무로 두 subtype으로 구분된다.
1) subtype 4-1. 짧은 자루의 두상선모

$20 \mu \mathrm{m}$ 이하의 짧은 자루를 지닌 두상선모로, $N$. affinis의 배축면(Fig. 3A), N. sinensis var. hypomalaca의 향축면, $P$. malvaceus의 양면(Fig. 4F), P. opulifolius의 향축면에서 관 찰되었다.

2) subtype 4-2. 자루가 없는 두상선모

자루가 없이 잎 표면에 납작하게 위치한 두상선모로, $N$. 

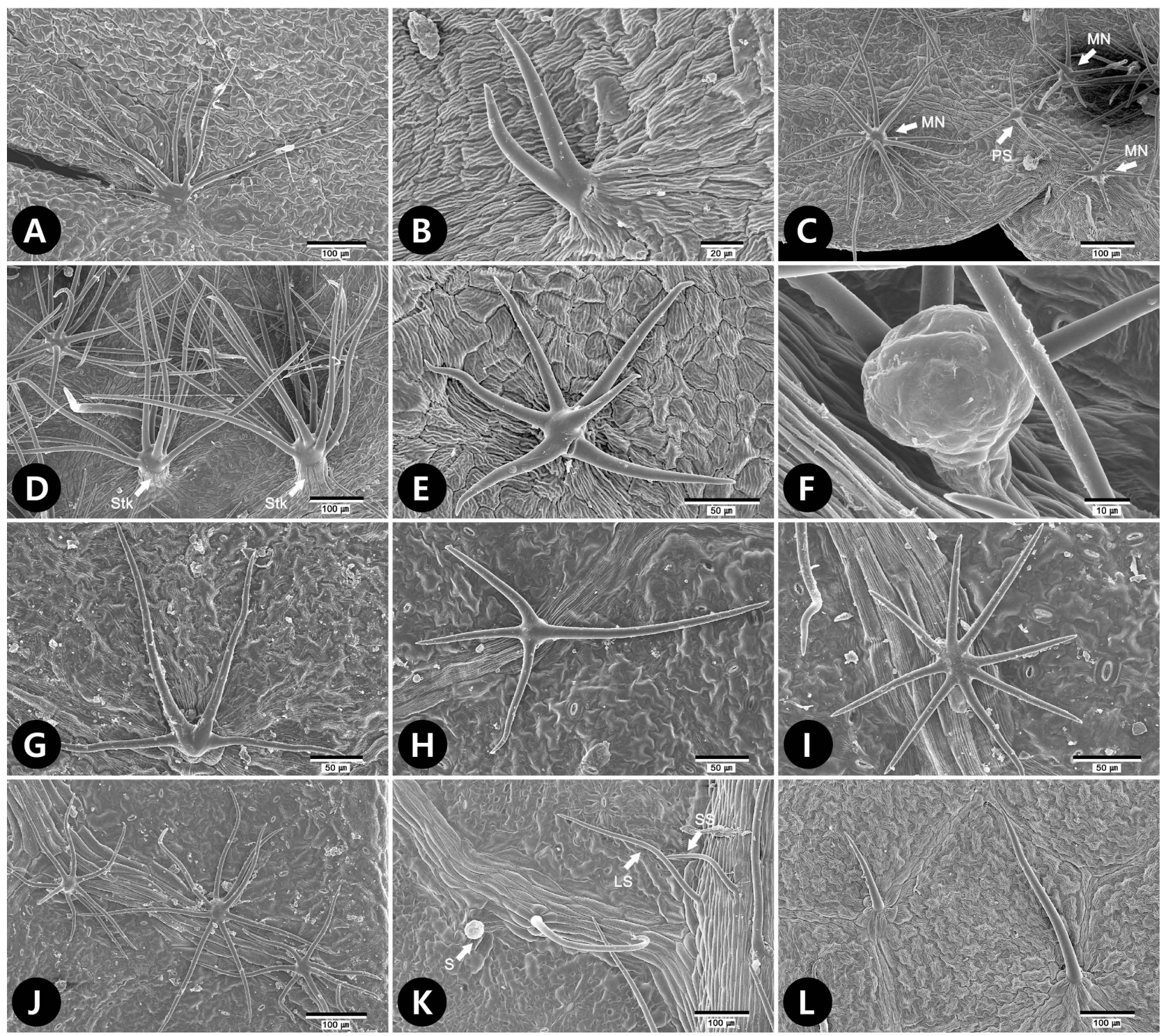

Fig. 4. Scanning electron microscope micrographs of trichomes of tribe Neillieae. A. Physocarpus amurensis. Multi-angulate stellate trichome (MN, type 3-2). B-F. Physocarpus malvaceus. B. Two armed trichome (AM, type 2). C. Distribution of porrect-stellate trichome (PS, type 31) and MNs (type 3-2) at abaxial surface. D. MN (type 3-2) with stalk (stk) at abaxial surface. E. MN (type 3-2) at adaxial surface. F. Capitate glandular trichome (type 4-1) abaxial surface. G-J. Physocarpus monogynus. G. Four AM (type 2) at adaxial surface. H. Four AM (type 2) at abaxial surface. I. Porrect-stellate trichome (PS, type 3-1). J. Distribution of PS (type 3-1) and MN (type 3-2) at abaxial surface. K, L. Stephanandra incisa. K. Distribution of short (SS, type 1-1), long trichomes (LS, type 1-2), and subsessile glandular trichome (S, type 4-2) at abaxial surface. L. LSs (type 1-2) at adaxial surface.

gracilis, N. sinensis var. hypomalaca (Fig. 3G), N. thyrsiflora (Fig. 3K), N. uekii, S. incisa (Fig. 4K)의 배축면, P. malvaceus 의 양면(Fig. $4 \mathrm{~F})$ 에 분포한다.

\section{고 찰}

나도국수나무족 3 속 15 분류군에 대하여 잎 표피 미세형 태학적 형질(기공복합체의 유형, 공변세포의 크기, 표피
세포의 미세형태 및 표피상납질의 유무, 모용의 유형)을 자세히 관찰하고, 기재하였다. 연구된 분류군에서는 기공 복합체의 유형, 표피세포의 미세형태, 모용의 유형에서 형질의 다양성을 확인하였으며, 분류학적 및 계통학적 유 용성을 고찰하였다.

\section{기공복합체의 유형}

연구된 분류군 내에서 P. monogynus, P. opulifolius의 경우 
에서만 양면기공엽이 확인되었고, Neillia속, Stephanandra 속과 나머지 Physocarpus속 내 분류군에서는 이면기공엽 으로 관찰되었다. 대부분의 경우, 기공엽의 유형은 속 내 종 수준에서 일관성있게 나타나는 것이 일반적이나, 몇몇 분류군의 경우 속 내에서도 기공엽 유형의 종간 차이가 나 타나 구별된다(Adeniji and Ariwaodo, 2012). 본 형질로 Neillia 속, Stephanandra속의 유사성뿐만 아니라, Physocarpus속 내 종을 구분하는 인식형질로서의 가능성을 확인하였다. 한 편, 일반적으로 양면기공엽을 나타내는 경우, 배축면의 밀도가 향축면보다 높은 것으로 알려져 있는데(Esau, 1977), 본 연구에서 역시 양면기공엽을 나타내는 두 분류 군(P. monogynus, P. opulifolius $)$ 의 경우, 배축면의 밀도가 높 게 나타나 일반적인 양면기공엽의 밀도 패턴으로 확인되 었다.

기공복합체 유형의 경우, 평행형이 나타나는 Neillia affinis을 제외하면, 족 내 모든 분류군에서 불규칙형으로 일관성있게 확인된다. 피자식물군 내에서 기공복합체 유 형에 대한 계통진화학적 해석은 아직까지 불분명한 것으 로 나타난다(Cronquist, 1981). 따라서, 본 형질에 대한 계통 학적 해석에는 무리가 있으나, 족 내 일관성있게 나타나 는 형질임을 확인할 수 있었다.

\section{표피세포의 미세형태 및 표피상납질의 유무}

표피세포를 통해 확인할 수 있는 다양한 형질은 분류학 적으로 가치있는 정보를 제공한다(Barthlott, 1981; Stace, 1984). 본 연구 결과, 표피세포의 다양한 형질 중 수층벽과 병층벽의 형태가 유용함을 확인하였는데, Neillia속의 경 우 모든 분류군에서 등방형의 세포는 향축면에서 직선형/ 곡선형, 배축면에서 파상형으로 일관성있게 나타났으며, Stephanandra속의 경우 양면에서 파상형이 나타나 구별되 었다. 한편, 병층벽의 경우 Stephanandra속의 배축면에서 볼록하게 나타났고, 섬국수나무(P. insularis)에서만 배축 면에 유두상 세포로 확인되어 족 내 다른 분류군과 유일 하게 구별되었다.

표피상납질은 다양한 식물군 내에서 독특한 형태로 나 타나며, 표피상납질의 유무와 유형에 대한 형질은 분류학 적으로 매우 유용한 것으로 알려져 있다(Wilkinson, 1979; Barthlott et al., 1998; Barthlott et al., 2003; Ensikat et al., 2006). 본 연구에서는 판형의 표피상납질이 N. affinis, S. tanakae 두 분류군에서만 확인되었다. 표피상납질은 서식지의 환 경적, 생태적 영향을 많이 받는다고 보고된 바 있고 (Agrawal et al., 2009), 특히 건조한 서식환경에서 증산작용 으로 인한 수분 손실로부터 표피저항성을 높이기 위한 전 략으로 발달한다고 알려져 있다(Oliveira et al., 2003; Rotondi et al., 2003). 본 형질은 족 내 종 동정으로 유용함이 밝혀졌으나, 추후 서식지와 관련하여 줄기, 엽병 등 식물 체 전체에서의 표피상납질 분포 및 종류에 대한 보다 심 도있는 연구가 필요할 것으로 판단된다.

\section{모용의 유형}

본 연구 분류군에서는 크게 4종류의 모용이 확인되었 으며, 관찰된 모용의 유형은 일부 속간, 종간 진단형질로 서 유용성이 있음이 밝혀졌다. 현화식물군 내 잎 표피에 서 나타나는 모용은 비교 계통학적 연구에서 상당히 중요 한 역할을 해왔고, 다양한 분류군 내에서 분류학적 유용 성이 확인되었다(Theobald et al., 1979). 특히, 장미과 내에 서는 많은 연구 결과를 통해 잎 표피에서 확인할 수 있는 모용 형태의 분류학적 유용성이 이미 검증되었다(Eriksen and Yurstev, 1999; Kolodziejek, 2008; Faghir et al., 2010; Ganeva and Uzunova, 2010; Heo et al., 2013; Faghir et al., 2014; Song and Hong, 2016). 본 연구에서 확인된 모용은 Theobald et al. (1979)이 제시한 형태를 기반으로, 크게 4종 류, subtype을 포함, 총 7종류로 구분하였다. 특히, 나도국 수나무족내에서는 2-5개 가지상 모용(armed trichome)과 성상모(PS, MN)의 유무가 분류학적으로 매우 유용하였다 . 일반적으로 $2-5$ 개 가지상 모용은 가지의 개수에 따라 크 게 2 개의 가지, 3 개에서 5 개의 가지상 모용으로 구분된다. 또한, 2 개의 가지로 된 모용의 경우, 그룹 내에서 진단형질 로 유용하며, 3-5개 가지상 모용은 일반적으로 더 다양하 고, 성상모와 수지상(dendritic type) 모용과 연관이 있다고 알려져 있다(Theobald et al., 1979).

본 연구에서는 가지의 개수와 형태에 따라 크게 2-5개 가지상 모용과 6 개 이상의 가지로 구성된 별 모양(starshaped)의 성상모로 구분하였다. 연구된 분류군 내에서 25 개 가지상 모용은 P. malvaceus, P. monogynus에서만 나타 났으며, 두 타입의 성상모 $(\mathrm{PS}, \mathrm{MN})$ 는 섬국수나무 $(P$. insularis)를 제외한 Physocarpus 속 모든 분류군에서 확인 되었다. 따라서, 성상모의 유무는 족 내 Physocarpus속을 구분하는 매우 유용한 형질임이 밝혀졌고, 2-5개 가지상 모용은 속 내 종 동정에 유용함이 확인되었다. 또한, 섬국 수나무는 긴 단세포단모(LS)만이 확인되어, Physocarpus 속 내 나머지 분류군과 상이한 차이를 나타냈다.

\section{계통학적 유용성(systematic implication)}

최근 주사전자현미경을 이용하여 관찰된 잎 표피 미세 형질을 분자계통수와 비교하여, 형질의 계통학적 유용성 을 밝히는 연구가 이루어지고 있다(Moon et al., 2009, 2010; Liu et al., 2010). 따라서, 생식형질뿐 아니라 영양형질 중 잎 표피에서도 분류학적, 계통학적으로 유용성있는 형질 을 탐색할 수 있다. 나도국수나무족에 대한 분자계통학적 연구에서는 본 족을 Neillia속과 Stephanandra속의 통합을 통해, Neillia속, Physocarpus속 두 속으로 제안하고 있으며 (Oh and Potter, 2003, 2005; Oh, 2006, 2015, 2016; Potter et al., 2007), 섬국수나무(P. insularis)의 분류학적 위치를 Spiraea속으로 전속하여 S. insularis로의 재조합을 제안하 고 있다(Oh et al., 2010, Shin et al., 2011). 최근 수행된 본 족 의 미세형태학적 형질 중 화분학적 형질의 연구결과에 따 
르면, 정량적 형질을 포함하여 크게 유공상(perforate)인 Neillia속, Stephanandra속과 유선상(striate)인 Physocarpus 속으로 구분하여 분자계통학적 연구결과를 지지할 뿐 아 니라, 화분 표면 무늬의 계통학적 유용성까지 밝힌 바 있 다(Song et al., 2017a).

영양기관인 잎 표피 미세형질에 대한 본 연구에서는 기 공복합체의 형태, 표피세포의 유형, 모용의 형태 형질에서 계통학적 유용성을 확인할 수 있었다. 기공복합체의 경우, Neillia속, Stephanandra속에서 이면기공엽이 일관성 있게 나타났고, Physocarpus속에서는 이면기공엽과 양면기공엽 을 지닌 분류군이 함께 나타나 구별되었다. 또한, 모용의 경우 Physocarpus속에서만 성상모가 나타나, 성상모가 나 타나지 않는 Neillia속, Stephanandra속과 구별되며, 이들 두 속의 유사성을 나타내는 형질임을 확인할 수 있었다.

한편, 본 연구 결과 섬국수나무는 족 내 다른 분류군과 매우 상이한 형질패턴을 나타냈다. 표피세포의 경우, 섬 국수나무에서만 유두상의 표피세포 형태가 확인되었고, Physocarpus속 내 분류군임에도 불구하고, 속 내에서 일관 성있게 나타나는 성상모 역시 나타나지 않았다. 최근 수 행된 조팝나무족(Spiraeeae)의 잎 표피 미세형태형질 연구 에서는 Spiraea속 내 일부 분류군에서 유두상의 표피세포 와 단세포 단모가 나타나며, 성상모는 속 내 분류군 모두에 서 일관성있게 나타나지 않음이 밝혀졌다(Song, 2016). 또 한, 화분학적 형질을 통해서는 섬국수나무가 유선상의 화 분 표면무늬(Physocarpus속 유공상; Spiraea속 유선상)를 지니고, 포분질(sporopollenin)로 이루어진 소구상체 (orbicules)가 약실 내벽에 존재하지 않는 특징(Physocarpus 속 소구상체 존재; Spiraea속 소구상체 부재)을 지녀, Spiraea속 내 분류군과 유사한 것으로 나타났다(Song et al., 2017a, 2017b). 따라서, 관찰된 일부 잎 표피 미세형태학적 형질 역시 섬국수나무가 Spiraea속 분류군과 유사함을 나 타내는 추가적인 형질로 판명되었으며, 분류학적 위치를 Spiraea속으로 전속하여 Spiraea insularis로 인식한 Oh et al. (2010)의 분자계통학적 연구 결과를 지지하였다.

결론적으로, 주사전자현미경을 이용한 나도국수나무 족 3 속 15 분류군의 잎 표피 미세형태학적 형질 중, 기공복 합체 유형, 표피세포 형태, 표피상납질의 유무, 모용의 형 태 등의 형질이 족 내 속, 종 수준에서 식별형질로서 유용 함을 밝혔다. 또한, 분자계통학적 연구 결과와의 비교 고찰 을 통해 Stephanandra속의 Neillia속으로의 통합, 섬국수나 무(Physocarpus insularis)의 Spiraea속으로의 전속(Spiraea insularis)에 대한 타당성을 확인함과 동시에 기공복합체의 형태, 유두상 표피세포의 유무, 성상모의 유무 형질의 계 통학적 유용성을 확인하였다.

\section{Acknowledgments}

The authors would like to thank the directors of the herbaria of $\mathrm{KB}$, KHUS, and $\mathrm{WU}$ for permitting the examination of specimens through loans. Two anonymous reviewers, whose comments and corrections raised the work, are also acknowledged. This study is a part of the Ph.D. dissertation of the first author (J.-H. Song) and is supported by the Basic Science Research Program through the National Research Foundation of Korea (NRF) funded by the Ministry of Education, Sciences and Technology (NRF-2012R1A1A200 4149) to S.-P. Hong.

\section{Literature Cited}

Adeniji, K. A. and J. O. Ariwaodo. 2012. Comparative foliar epidermal studies of genus Pericopsis (Papilionaceae) in Nigeria. Phytologia Balcanica 18: 37-41.

Agrawal, A. A., M. Fishbein, R. Jetter, J. P. Salminen, J. B. Goldstein, A. E. Freitag and J. P. Sparks. 2009. Phylogenetic ecology of leaf surface traits in the milkweeds (Asclepias spp.): chemistry, ecophysiology, and insect behavior. New Phytologist 183: 848-867.

Anil Kumar, V. S. and K. Murugan. 2013. Taxonomic significance of foliar micromorphology and their systematic relevance in the genus Solanum (Solanaceae). In Prospects in Bioscience: Addressing the Issues. Sabu, A. and A. Augustine (eds.), Springer, New Delhi. Pp. 343-349.

Barthlott, W. 1981. Epidermal and seed surface characters of plants: systematic applicability and some evolutionary aspects. Nordic Journal of Botany 1: 345-355.

Barthlott, W., C. Neinhuis, D. Cutler, F. Ditsch, I. Meusel, I. Theisen and H. Wilhelmi. 1998. Classification and terminology of plant epicuticular waxes. Botanical Journal of the Linnean Society 126: 237-260.

Barthlott, W., I. Theisen, T. Borsch and C. Neinhuis. 2003. Epicuticular waxes and vascular plant systematics: integrating micromorphological and chemical data. In Deep Morphology: Toward a Renaissance of Morphology in Plant Systematics. Stuessy, T. F., V. Mayer and E. Hörandl (eds.), ARG Gantner Verlag, Ruggell. Pp. 189-206.

Bentham, G. and J. D. Hooker. 1865. Genera Plantarum, Vol. 1. William Pamplin, London, 516 pp.

Cronquist, A. 1981. An Integrated System of Classification of Flowering Plants. Columbia University Press, New York, $1262 \mathrm{pp}$.

Dahlgren, R. M. T. 1980. A revised system of classification of the angiosperms. Botanical Journal of the Linnean Society 80 : 91-124.

De Sá-Haiad, B., A. C. C. Serpa-Ribeiro, C. N. Barbosa, D. Pizzini, D. D. O. Leal, L. de Senna-Valle and L. D. R. De San- 
tiago-Fernandes. 2009. Leaf structure of species from three closely related genera from tribe Crotoneae Dumort. (Euphorbiaceae s.s., Malpighiales). Plant Systematics and Evolution 283: 179-202.

Deng, M., A. Hipp, Y.-G. Song, Q.-S. Li, A. Coombes and A. Cotton. 2014. Leaf epidermal features of Quercus subgenus Cyclobalanopsis (Fagaceae) and their systematic significance. Botanical Journal of the Linnean Society 176: 224-259.

Ensikat, H. J., M. Boese, W. Mader, W. Barthlott and K. Koch. 2006. Crystallinity of plant epicuticular waxes: electron and X-ray diffraction studies. Chemistry and Physics of Lipids 144: 45-59.

Eriksen, B. and B. A. Yurstev. 1999. Hair types in Potentilla sect. Niveae (Rosaceae) and related taxa, terminology and systematic distribution. Norske Videnskaps-Akademi Matematisk.Naturvidenskapelig Klasse 38: 201-221.

Esau, K. 1977. Anatomy of Seed Plants. 2nd ed. John Wiley and Sons, New York, 576 pp.

Faghir, M. B., F. Attar, A. Farazmand, B. Ertter and B. Eriksen. 2010. Leaf indumentum types in Potentilla (Rosaceae) and related genera in Iran. Acta Societatis Botanicorum Poloniae 79: 139-145.

Faghir, M. B., K. K. Chaichi and R. S. Shahvon. 2014. Foliar epidermis micromorphology of the genus Alchemilla (Rosaceae) in Iran. Phytologia Balcanica 20: 215-225.

Ganeva, T. and K. Uzunova. 2010. Comparative leaf epidermis study in species of genus Malus Mill. (Rosaceae). Botanica Serbica 34: 45-49.

Greene, E. L. 1889. The North American Neilliæ. Pittonia 2: 2531.

Heo, K. I., S. R. Lee, M. H. Yoo, S. T. Lee, Y. Kwon, S. Y. Lim, S. H. Kim and S. C. Kim. 2013. The taxonomic implication of trichome and epicuticular waxes in tribe Potentilleae (Rosaceae) in Korea. Korean Journal of Plant Taxonomy 43: 106117. (in Korean)

Husain, S. Z., P. D. Marin, Č. Šilić, M. Qaiser, and B. Petcović. 1990. A micromorphological study of some representative genera in the tribe Saturejeae (Lamiaceae). Botanical Journal of the Linnean Society 103: 59-80.

Jones, M. E. 1893. Contributions to western botany. Zoe 4: 38-45. Kalkman, C. 2004. Rosaceae. In The Families and Genera of Vascular Plants, Vol. 6. Flowering Plants - Dicotyledons: Celastrales, Oxalidales, Rosales, Cornales, Ericales. Kubitzki, K. (ed.), Springer-Verlag, Berlin. Pp. 343-386.

Kim, C. H., T. J. Kim and B.-Y. Sun. 2000. Taxonomic identities of some endemic Korean vascular plants. Korean Journal of Plant Taxonomy 30: 355-361. (in Korean)

Kołodziejek, J. 2008. Hair types in Polish selected taxa of Poten- tilla subsect. Collinae (Rosaceae). Acta Societatis Botanicorum Poloniae 77: 217-224.

Kuntze, O. 1891. Revisio Generum Plantarum, Parts 1. Arthur Felix, Leipzig, 374 pp.

Liu, Q., D. X. Zhang and P. M. Peterson. 2010. Lemma micromorphological characters in the Chloridoideae (Poaceae) optimized on a molecular phylogeny. South African Journal of Botany 76: 196-209.

Ma, Q.-W., C.-S. Li, F.-L. Li and S. V. Vickulin. 2004. Epidermal structures and stomatal parameters of Chinese endemic Glyptostrobus pensilis (Taxodiaceae). Botanical Journal of the Linnean Society 146: 153-162.

Maximowicz, C. J. 1879. Adnotationes de Spiraeaceis. Trudy Imperatorskago S.-Peterburgskago Botanicheskago Sada 6: 105-261.

Moïse, J. A., S. Han, L. Gudynaite _-Savitch, D. A. Johnson and B. L. A. Miki. 2005. Seed coats: structure, development, composition, and biotechnology. In Vitro Cellular \& Developmental Biology-Plant 41: 620-644.

Moon, H.-K., S.-P. Hong, E. Smets and S. Huysmans. 2009. Phylogenetic significance of leaf micromorphology and anatomy in the tribe Mentheae (Nepetoideae: Lamiaceae). Botanical Journal of the Linnean Society 160: 211-231.

Moon, H.-K., E. Smets and S. Huysmans. 2010. Phylogeny of tribe Mentheae (Lamiaceae): the story of molecules and micromorphological characters. Taxon 59: 1065-1076.

Morgan, D. R., D. E. Soltis and K. R. Robertson. 1994. Systematic and evolutionary implications of $r b c \mathrm{~L}$ sequence variation in Rosaceae. American Journal of Botany 81: 890-903.

Oh, S.-H. 2006. Neillia includes Stephanandra (Rosaceae). Novon 16: $91-95$.

Oh, S.-H. 2015. Taxonomy of tribe Neillieae (Rosaceae): Physocarpus. Korean Journal of Plant Taxonomy 45: 332-352.

Oh, S.-H. 2016. Taxonomy of tribe Neillieae (Rosaceae): Neillia. Korean Journal of Plant Taxonomy 46: 13-32.

Oh, S.-H. and D. Potter. 2003. Phylogenetic utility of the second intron of LEAFY in Neillia and Stephanandra (Rosaceae) and implications for the origin of Stephanandra. Molecular Phylogenetics and Evolution 29: 203-215.

Oh, S.-H. and D. Potter. 2005. Molecular phylogenetic systematics and biogeography of tribe Neillieae (Rosaceae) using DNA sequences of cpDNA, rDNA, and LEAFY. American Journal of Botany 92: 179-192.

Oh, S.-H., L. Chen, S.-H. Kim, Y.-D. Kim and H. Shin. 2010. Phylogenetic relationship of Physocarpus insularis (Rosaceae) endemic on Ulleung Island: implications for conservation biology. Journal of Plant Biology 53: 94-105.

Oliveira, A. F. M., S. T. Meirelles and A. Salatino. 2003. Epicu- 
ticular waxes from caatinga and cerrado species and their efficiency against water loss. Anais da Academia Brasileira de Ciências 75: 431-439.

Potter, D., F. Gao, P. E. Bortiri, S.-H. Oh and S. Baggett. 2002. Phylogenetic relationships in Rosaceae inferred from chloroplast matK and $t r n \mathrm{~L}-t r n \mathrm{~F}$ nucleotide sequence data. Plant Systematics and Evolution 231: 77-89.

Potter, D., T. Eriksson, R. C. Evans, S. Oh, J. E. E. Smedmark, D. R. Morgan, M. Kerr, K. R. Robertson, M. Arsenault, T. A. Dickinson and C. S. Campbell. 2007. Phylogeny and classification of Rosaceae. Plant Systematics and Evolution 266: 543.

Rehder, A. 1940. The Manual of Cultivated Trees and Shrubs Hardy in North America Exclusive of the Subtropical and Warmer Temperate Regions. 2nd ed. Macmillan, New York, 996 pp.

Robertson, K. R. 1974. The genera of Rosaceae in the southeastern United States. Journal of the Arnold Arboretum 55: 303332.

Rotondi, A., F. Rossi, C. Asunis and C. Cesaraccio. 2003. Leaf xeromorphic adaptations of some plants of a coastal Mediterranean macchia ecosystem. Journal of Mediterranean Ecology 4: $25-35$.

Schulze-Menz, G. K. 1964. Rosaceae. In Engler's Syllabus der Pflanzenfamilien II. 12th ed. Melchior H. (ed.), Gebrüder Borntraeger, Berlin. Pp. 209-218.

Shin, H., Y.-D. Kim and S.-H. Oh. 2011. A new combination in Spiraea (Rosaceae) from Ulleung Island, Korea. Novon 21: 373-374.

Song, J.-H. 2016. Systematic studies in Spiraeoideae (Rosaceae). Ph.D. dissertation, Kyung Hee University, Seoul, Korea, 335 pp.

Song, J.-H. and S.-P. Hong. 2016. Taxonomic significance of the leaf micromorphology in the tribe Sorbarieae (Spiraeoideae: Rosaceae). Korean Journal of Plant Taxonomy 46: 199-212. (in Korean)

Song, J.-H., H.-K. Moon, M.-K. Oak and S.-P. Hong. 2017a. Phylogenetic evaluation of pollen and orbicule morphology in the Rosaceae tribe Neillieae (subfamily Amygdaloideae). Botanical Journal of the Linnean Society 183: 439-453.

Song, J.-H., M.-K. Oak, H.-S. Roh and S.-P. Hong. 2017b. Morphology of pollen and orbicules in the tribe Spiraeeae (Rosaceae) and its systematic implications. Grana 56: 351-367.

Stace, C. A. 1984. The taxonomic importance of the leaf surface. In Current Concepts in Plant Taxonomy. Heywood, V. H. and D. M. Moore (eds.), Academic Press, London. Pp. 67-93.

Taia, W. K. 2004. Leaf characters within tribe Trifolieae (family Leguminosae). Pakistan Journal of Biological Sciences 7: 1463-1472.

Takhtajan, A. 1997. Diversity and Classification of Flowering Plants. Columbia University Press, New York, 620 pp.

Theobald, W. L., J. L. Krahulik and R. C. Rollins. 1979. Trichome description and classification. In Anatomy of the Dicotyledons. 2nd ed. Vol. I. Metcalfe, C. R. and L. Chalk (eds.), Clarendon Press, Oxford. Pp. 40-53.

Thiers, B. 2017. (Continuously updated) Index Herbariorum: a global directory of public herbaria and associated staff. New York Botanical Garden's Virtual Herbarium. Retrieved Sep. 1, 2016, Available from http://sweetgum.nybg.org/ih/.

Vidal, J. 1963. Le genre Neillia (Rosaceae). Adansonia 3: 142166.

Wilkinson, H. P. 1979. The plant surface (mainly leaf). In Anatomy of the Dicotyledons. 2nd ed. Vol. I. Metcalfe, C. R. and L. Chalk (eds.), Clarendon Press, Oxford. Pp. 97-165.

Yang, Z.-R. and Q. Lin. 2005. Comparative morphology of the leaf epidermis in Schisandra (Schisandraceae). Botanical Journal of the Linnean Society 148: 39-56.

Zoric, L., L. Merkulov, J. Lukovic, P. Boza and D. Polic. 2009. Leaf epidermal characteristics of Trifolium L. species from Serbia and Montenegro. Flora 204: 198-209. 
Appendix 1. Voucher specimens of tribe Neillieae that are examined in the present study.

Taxa

Neillia affinis Hemsl.

Austria, Cultivated in H.B.V., 26 May 1961, Fùmlnauz s.n. WU

China, Sichuan Prov., 1906-1908, Wilson 916 a A

Neillia gracilis Franch.

Neillia sinensis Oliv. var. sinensis

China, Sichuan Prov., 13 Jun 1914, Handel-Mazzetti 598 WU*

Austria, Cultivated in H.B.V., 26 May 1961, Fùmlnauz s.n. WU China, Hunan Prov., Apr 1919, Wang-Ts-Hui 12010 WU*

Neillia sinensis var. hypomalaca (Rehder) Hand.-Mazz.

China, Sichuan Prov., 24 Apr 1914, Handel-Mazzetti 391 WU*

Neillia thibetica Bureau \& French. var. thibetica

China, Sichuan Prov., 8 Jun 1914, without collector 1558 WU* $^{*}$

Neillia thibetica var. lobata (Rehder) T. T. Yu

China, Sichuan Prov., 31 May 1914, Handel-Mazzetti 511 WU*

Neillia thyrsiflora D. Don.

Neillia uekii Nakai

Physocarpus amurensis (Maxim.) Maxim.

China, Yunnan Prov., 7 Jun 1916, Handel-Mazzetti 1772 WU*

Korea, Gyeonggi-do, Mt. Cheonggye-san, 19 May 2012, Song and Ok 17220519 KHUS*

China, Hebei Prov., 7 Jul 1917, without collector 2920 WU* $^{*}$

Russia, Primorye, Dahleongorsk, 25 Jul 2002, Sun et al. 2309 KH

†Physocarpus insularis (Nakai) Nakai

Physocarpus malvaceus (Green) Kuntze

Physocarpus monogynus (Torr.) Coult.

Physocarpus opulifolius (L.) Maxim.

"Stephanandra incisa (Thunb.) Zabel

Korea, Ulleung island, 9 May 2006, Hyun et al. NAPI-20101210 KB*

USA, Idaho, Idaho Co., 10 Jul 1916, Macbride and Payson 3117 WU*

Austria, Cultivated in H.B.V., 9 May 1950, Cufodontis 3316 WU

USA, Colorado, Clear Creek County Seat Co., 3 Jul 1885, Patterson $23 \mathrm{WU}^{*}$

Austria, Cultivated in H.B.V., 26 May 1961, Fùmlnauz s.n. WU

USA, Washington, D.C., 26 May 1896, Steele s.n. WU*

Japan, Yokohama, Kanagawa-ku, Mt. Bukka-san, 21 May 1976, Midorikawa s.n. KH Korea, Gyeonggi-do, Mt. Cheonggye-san, 23 May 2012, Song and Ok 17230523 KHUS*

${ }^{*}$ Stephanandra tanakae (Franch. \& Sav.) Franch. \& Sav.

Japan, Honshu, Shizuoka, Fujimiya, 19 Jun 1983, Togashi C383353-12 WU*

Symbols "currently transferred from Physocarpus to Spiraea by Shin et al. (2011) and *proposed members of Stephanandra combined into Neillia by Oh (2006, 2016). Herbarium acronyms follow Index Herbariorum (Thiers, 2017) [continuously updated] http://sweetgum.nybg.org/science/ih/. 